\title{
Inovação $x$ eficiência: um estudo empírico para o Polo Industrial de Manaus (2000-2006)
}

\author{
Márcia Jucá Teixeira Diniz ${ }^{1}$ \\ Marcelo Bentes Diniz ${ }^{2}$ \\ José Nilo de Oliveira Júnior ${ }^{3}$
}

Resumo: A partir do aporte teórico da chamada teoria Neo-Schumpeteriana no que tange o papel das inovações nos processos produtivos das empresas, investigase, para o período 2000-2006, a relação entre a adoção de inovações e seu efeito sobre a eficiência econômica nas empresas localizadas no Pólo Industrial de Manaus (PIM). Utiliza-se para este fim o método paramétrico conhecido como Análise de Fronteira Estocástica de Produção com o objetivo de estimar a eficiência produtiva das empresas, controlando para a introdução de inovações. Os dados da pesquisa compreenderam dois níveis: secundários - oriundos da Superintendência da Zona Franca de Manaus (SUFRAMA), e que se referem aos indicadores econômicos de desempenho das empresas; e primários - coletados através da aplicação de um questionário às empresas do PIM cadastradas nessa Instituição. As principais conclusões referem-se à significância da inovação, principalmente, ambiental sobre eficiência, medida pelo faturamento das empresas.

Palavras-chave: Inovação; Eficiência econômica; Polo Industrial de Manaus.

1 Professora do Programa de Pós-Graduação em Economia da Universidade Federal do Pará (UFPA). E-mail: mjucadiniz@ufpa.br

2 Professor do Programa de Pós-Graduação em Economia da Universidade Federal do Pará (UFPA). E-mail: mbdiniz@ufpa.br

3 Professor do Programa de Pós-Graduação em Economia da Universidade Federal do Pará (UFPA). E-mail: josenilo@ufpa.br 


\begin{abstract}
This article relies on the Neo-Schumpeterian theory of technical change in the production process of firms operating in the Industrial Polo of Manaus (PIM). It was investigated, for the period 2000-2006, the relationship between the adoption of innovations and its effects concerns economic efficiency in the companies located in the Industrial Polo of Manaus (PIM). Using the stochastic production frontier method, the study estimated productive efficiency of the PIM's firms controlling by innovations. This research is supported by two datasets from both primary and secondary sources: secondary data - provided by the Superintendency of Free Trade Zone of Manaus (SUFRAMA) which refers to economic performance indicators of firms in the PIM; the primary data are from a survey realized in the PIM among firms registered at SUFRAMA. The main results derived from the model point out a significant role the innovations to explaining performance of more efficient firms.
\end{abstract}

Keywords: Innovation; Economic efficiency; Industrial Polo of Manaus.

JEL: O31; L10; C33.

\title{
Introdução
}

O Polo Industrial de Manaus - PIM, integra desde a sua criação, a Superintendência da Zona Franca de Manaus - SUFRAMA, em 1967, através do Decreto-Lei $n^{0}$ 288, como parte de um novo redirecionamento geopolítico para região Amazônica que se inaugura com o primeiro governo militar.

Na realidade, o chamado modelo Zona Franca de Manaus - ZFM é composto, além do PIM localizado na capital do estado do Amazonas, de mais dois diferentes arranjos institucionais legais, a saber: o Distrito Agropecuário da SUFRAMA (DAS), com incentivos fiscais voltados ao setor primário, cuja área de abrangência compreende os municípios de Manaus, Rio Preto e Presidente Figueiredo, todos pertencentes ao estado do Amazonas; e as Áreas de Livre Comércio, integradas pelas localidades de fronteira da sub-região da Amazônia Ocidental e ainda os municípios de Macapá e Santana, ambos pertencentes ao estado do Amapá na sub-região da Amazônia Oriental (RIVAS et al., 2009).

De sua criação, alicerçado no chamado Modelo de Substituição de Importações, até os dias atuais, o PIM vem sofrendo transformações de natureza estrutural ${ }^{4}$, em parte relacionada à política econômica vigente em cada governo e a posição "estratégica" que é dada a Amazônia; em parte provocada pelas mudanças do ambiente competitivo, especialmente externo, que impõem processos de reestruturação produtiva constantes às empresas em todos os níveis, e, em muitos casos, a partir da decisão das matrizes de cada empresa, nacional e multinacional - situadas fora do PIM.

4 Transformações ou reconstruções internas no Pólo Industrial de Manaus afetas: à dinâmica organizacional dos setores industriais (relações internas de empresas e fornecedores); a infra-estrutura básica (energia, água, esgoto, rodovias, estradas) e logística capaz de agilizar o transporte e a distribuição dos produtos, no intuito de sua sustentação e sua manutenção. 
Na década de 1990, e mais fortemente, nos anos 2000, com a maior competição externa decorrente a abertura da economia nacional, altera-se a legislação da ZFM (Lei no 8.387/1991), para dar conta de um contexto que exigia maiores investimentos em Pesquisa e Desenvolvimento, ganhos constantes de eficiência (produtividade) e, portanto, que se pudesse internalizar e difundir inovações.

Nesse contexto três alterações foram fundamentais: i) mudança do critério de acompanhamento do nível de industrialização praticada pelos projetos incentivados em Manaus, baseado no chamado Processo Produtivo Básico $\mathrm{PPB}$, cuja lógica era estabelecer o conjunto mínimo de etapas que permitiria caracterizar um efetivo processo de industrialização, com agregação de valor e sem restrições quanto à aquisição de insumos e componentes; ii) incorporação de mecanismos de avaliação e difusão da qualidade, como a obrigatoriedade de implantação de sistemas de normalização (ex. ISO 9000), inspirados no Programa Nacional de Qualidade e Produtividade (PNQP); iii) incorporação de mecanismos de indução de Pesquisa e Desenvolvimento (P\&D), através do estabelecimento da obrigatoriedade da aplicação de parte do faturamento bruto das indústrias de bens de informática em P\&D (Rivas et al., 2009).

Esta última fase denominada de High Tech5 (Machado et al. 2006) dá uma nova natureza à competitividade das empresas situadas no PIM, tendo estas que se adaptarem de forma crescente as exigências do mercado externo, em todas as fases do seu processo produtivo e em todo o ciclo dos seus produtos. Incluem-se as inovações para atender as exigências de caráter ambiental, relacionadas aos investimentos das empresas relacionados à certificação de origem, implantação de tecnologias limpas em todas as etapas de transformação produtiva, aquisição de insumos, descarte dos produtos, aumento da reutilização de insumos energéticos e reciclagem.

Assim, o objetivo deste artigo é discutir esse processo de adoção de introdução de inovações pelas empresas situadas no PIM, apresentar os resultados setoriais e verificar a relação entre estas inovações e a eficiência econômica das empresas nos diferentes subsetores que compõem o PIM.

Utiliza-se, para tanto, a técnica paramétrica de fronteira estocástica, bem como dados primários e secundários. Os primeiros foram coletados através de questionários aplicados a uma amostra de 153 empresas integrantes do PIM no ano de 2006. O segundo conjunto de dados tem como fonte o banco de indicadores econômicos da SUFRAMA e correspondem ao período de 2000 a 2006.

Vale observar, que o método da fronteira estocástica de produção (Aigner; Lovell; Schmidt, 1977; Meusen; Broeck, 1977; Battese; Coelli; 1995) tem como uma das vantagens, a incorporação além dos distúrbios aleatórios relativo à função de produção, efeitos de ineficiência técnica (Marinho; Bittencourt, 2007).

5 Setores de alta tecnologia como Eletroeletrônicos Bens Finais, Eletroeletrônicos Componentes, Duas Rodas, Bens de Informática, como definidos no site da SUFRAMA: (www.suframa.gov.br). 
O artigo está organizado em cinco seções. A segunda faz uma breve caracterização do papel da inovação (ambiental) no âmbito da teoria evolucionária. A terceira faz uma descrição do desempenho recente do PIM. A quarta apresenta os resultados do modelo empírico utilizado, em que se testa o efeito da inovação sobre a eficiência das empresas, com base em um modelo de fronteira estocástica. A última seção é dedicada às considerações finais.

\section{A teoria evolucionária e o papel da inovação (ambiental): uma breve introdução}

Sob o escopo da teoria neo-schumpeteriana, as inovações estão inseridas numa visão dinâmica e evolucionária do funcionamento da economia capitalista, em um processo contínuo de concorrência entre as empresas.

Na teoria evolucionária, o foco se dá sobre diferentes aspectos de mudanças econômicas: as respostas das firmas e da indústria diante mudanças nas condições de mercado, no crescimento econômico, e na competição através da inovação. As firmas são modeladas como tendo, a qualquer tempo, certas capacidades e regras de decisões. Essas capacidades e regras são modificadas no tempo como resultado de problemas e soluções e de eventos aleatórios que vão surgindo (Nelson; Winter, 1982) ${ }^{6}$.

As firmas, nesse modelo analítico, empreendem atividades de inovação e imitação em função do seu tamanho e de sua posição face às empresas situadas na fronteira tecnológica.

As diferentes combinações produtivas implicam em diferentes oportunidades e capacidades tecnológicas ${ }^{7}$ para o futuro, tal que dentro de cada tecnologia e de cada setor as capacidades tecnológicas das empresas se encontram vinculadas aos atuais processos produtivos. E, ao mesmo tempo, o padrão tecnológico se encontra, ajustado aos esquemas atuais de dotações de recursos e de produção (Cimoli; Dosi; Stiglitz, 2008).

O setor empresarial geralmente empreende atividades inovadoras quando elas buscam alguma expectativa de retorno econômico, ou quando a falta de tais atividades acarreta a ameaça de perda de alguns benefícios econômicos, ou pelos dois motivos ${ }^{8}$. Por isso as empresas devem levar em consideração as características dos avanços tecnológicos que inclui três conceitos importantes (Dosi, 2006) a) cumulatividade do progresso técnico - efeitos cumulativos no âmbito da empresa incentivando-a a inovar; b) oportunidade tecnológica - em geral, surgem em setores produtivos onde já ocorreram inovações

6 Juntamente com Giovanni Dosi são "precursores" da Teoria Evolucionária.

7 A Capacidade Tecnológica de uma empresa constitui-se no conjunto de habilidades que sustentam as rotinas de produção e de melhoramentos da empresa. Essas habilidades localizam-se nas linhas de produção e em departamentos especializados (Furtado, 1994).

8 Além de retornos econômicos as empresas preocupam-se também com marcas, market share, market share verde, e outros indicadores capazes de se conformarem como vantagens competitivas. 
e assim tornando mais fácil a realização de novas mudanças técnicas e aperfeiçoamentos; c) apropriabilidade privada - equivalente ao grau de controle que o inovador - empresa - possui sobre os resultados econômicos da mudança técnica.

O paradigma tecnológico é necessário para deslocar novas possibilidades técnicas de produto e processos inovadores e fluem entre as diferentes comunidades com as mesmas dificuldades que entre mercados. Em consequência, geram distintas direções e "trajetórias tecnológicas" (path dependence).

Segundo Dosi (2006), a mudança técnica tem um ritmo acelerado causando assim, alterações na demanda por diversos produtos, nos custos unitários, na determinação de economias de escala e de possibilidades de descontinuidades tecnológicas das empresas.

No contexto geral, a capacidade tecnológica de uma firma, ou mesmo do setor industrial, pode ser formada por quatro componentes que apresentam um elevado grau de complementariedade entre si (Bell; Pavitt, 1993): Sistemas Físicos: formado por máquinas e equipamentos, base de dados e softwares; Capital humano: que engloba tanto o conhecimento tácito, como as experiências e habilidades adquiridas ao longo do tempo por trabalhadores no processo produtivo; Sistema organizacional: que se refere ao conhecimento acumulado nas rotinas organizacionais e gerenciais das firmas; Produtos e serviços: que refletem o conhecimento tácito dos indivíduos, da organização e dos outros sistemas: físicos e organizacionais, materializados em atividades como: desenho, desenvolvimento, teste, produção e comercialização.

Ademais, o desenvolvimento das chamadas aptidões tecnológicas das firmas depende de um conjunto amplo de fatores, em geral internos as mesmas, mas também, fatores externos relacionados ao ambiente (macro) econômico em que ela atua e da competição de mercado. Assim, por exemplo, como assina Lall (2005), concorre, em geral, de forma consciente e intencional, o aprendizado ${ }^{9}$, em um processo que tende a depender de sua trajetória, em uma evolução acumulativa, embora não ocorra de forma homogênea e autônoma. É ele mesmo dependente desta tecnologia e de quão rápida ocorre a sua evolução, inclusive, quanto ao grau de interação da mesma, a fontes externas de conhecimento e informação, como outras empresas, fornecedores, consultores, ou instituições de P\&D, externalidades e interconexões, como bem acentuou Stiglitz (1997), que ocorrem na competição no mercado.

Conquanto possa ser feita uma divisão entre as inovações e, por sua vez, das teorias da inovação impulsionadas pela ciência (Science-push) ou induzidas pela demanda (demand-pull) (Langrish et al., 1972) - existem evidências que podem sustentar ambas estas visões. Conforme Freeman \& Soete (2008), de um lado, pode haver casos em que a inovação pode resultar da descoberta

9 Aprendizado, cujo sentido é resumido por Teece (2005, p. 154): “um processo pelo qual a repetição e a experimentação permitem que as tarefas sejam mais bem e mais rapidamente desempenhadas e que as novas oportunidades de produção sejam identificadas”. 
científica como indutoras de um mercado, como também, que o próprio mercado, isto é, a incorporação de um novo mercado para um produto já existente, constitua-se por si em uma inovação.

Desta feita, a crescente inserção da questão ambiental na esfera produtiva pode ser entendida como um "dado novo (uma inovação)"10 dentro do ambiente evolucionário/dinâmico (Nelson; Winter, 1982; Dosi; Cimoli, 1992; Rosenberg, 2006) que constrange as empresas “inserindo" nelas o problema ambiental.

Incorpora-se, neste contexto, a percepção de que a preservação ambiental no âmbito das empresas traria bons frutos para os negócios, ou seja, a relação antes vista como inversa entre preservação ambiental e lucratividade, passa a dar lugar à idéia de que a variável ambiental pode ser um elemento indutor na busca de competitividade.

A tônica é a compreensão de que a renúncia à proteção ambiental custa dinheiro para as empresas, uma vez que passam a existir restrições explícitas, tanto pelo lado da demanda como pelo lado da oferta, que impõem essa mudança de postura das empresas com relação à variável ambiental, em alguns casos não só para garantir posição competitiva, mas antes garantir sua sobrevivência no mercado - lucratividade.

Pelo lado da demanda, pode-se considerar a pressão da sociedade em relação à mudança de postura das empresas, no qual concorrem cinco "steakholders" importantes nesse processo (Esty; Winston, 2008): os reguladores do governo e os grupos de defesa do meio ambiente; os geradores de idéias e líderes de opinião, que incluem a participação dos meios acadêmicos; os parceiros de negócios e concorrentes; consumidores e comunidade; investidores e avaliadores de riscos, em particular, agências de financiamento e bancos ${ }^{11}$. No qual atuariam em conjunto, com quatro importantes instrumentos de políticas voltados às empresas privadas para que invistam no desenvolvimento de tecnologias sustentáveis. São elas: a regulação direta, os diversos instrumentos econômicos, as compras governamentais e políticas para alterar o ambiente social das mudanças técnicas (Freeman; Soete, 2008).

Desta feita, as inovações ambientais são definidas, dentro do arcabouço teórico de Schumpeter, como: inovações que ocorrem em tecnologias ou processos ambientais que controlam a emissão de poluição ou alteram o processo produtivo para reduzir ou prevenir as emissões de poluentes. Ademais, essas inovações/tecnologias são distinguidas por terem um papel vital na manutenção dos "bens públicos", enquanto um ambiente limpo (Stern, 2007).

Assim, os "problemas ambientais" podem se transformar em oportunidades de negócios ambientais - formação de Ecovantagens Competitivas - que se

10 Adiante será definido o conceito de Inovação ambiental.

11 Consagrados entre outros no chamado: "Princípios do Equador" (2006), que servem como base para avaliação de riscos por agências financeiras para financiamento de projetos. 
incorporam as estratégias competitivas das empresas, gerando inovação, criando e agregando valor, elementos estes, que caracterizam a chamada Onda Verde da Economia Mundial na perspectiva de uma empresa sustentável ${ }^{12}$ (Esty; Winston, 2008).

Ao mesmo tempo, as vantagens competitivas ligadas ao meio ambiente, e as decisões das empresas, passam a ser fortemente afetadas, de um lado por imposições não - legais (Dasgupta; Hettige; Wheeler, 200o) e, por outro, a depender do tamanho da planta, por aplicações regulatórias ou exigências ambientais (Gray; Deily, 1996). Até por que a ecovantagem é avaliada ao longo do ciclo de vida do produto, podendo a empresa obter vantagem competitiva, ao longo do processo produtivo, a partir do uso mais eficiente de insumos energéticos, reutilização e reciclagem, ou através de um descarte do produto de modo ambientalmente seguro, que para tanto, desde sua concepção preconiza a substituição de matérias-primas, e um design mais apropriado para este fim (Thomas; Callan, 2007).

\section{O Polo Industrial de Manaus: histórico recente}

A partir da década de 1990, inicia-se uma fase de modernização industrial high-tech num ambiente globalizado. As indústrias incentivadas de Manaus sentiram as conseqüências da abertura comercial brasileira, aliada, a política de estabilização monetária do período de 1993/1994. Decorrente das conseqüências da competição externa, tais indústrias, viram-se obrigadas a alterar substancialmente sua função de produção, passando a serem mais intensivas em capital e tecnologia, no qual passou a promover um esforço de modernização cujas velocidades e profundidade dificilmente possuem paralelo na história industrial brasileira ${ }^{13}$.

Também na década de 1990, as importações estavam liberadas, caía à exigência de índices mínimos de nacionalização, e a concessão de incentivos ficais se tornava mais flexível, condicionando-se ao cumprimento do Processo Produtivo Básico (PPB) definido na Lei 8.387 como o conjunto mínimo de operações no estabelecimento fabril, que caracteriza a efetiva industrializa-

\footnotetext{
12 Firmas capazes de gerar um valor sustentável, isto é, atuam na direção da promoção da sustentabilidade, como um objetivo que não se limita a obter fluxos financeiros e encara os clientes, fornecedores e comunidade, em geral, como parceiros sociais (Laszlo, 2007; Laville, 2009), na mesma ótica do que define o Índice do Grupo de Sustentabilidade do Dow Jones (DJSGI).

13 Algumas mudanças eram necessárias: extinguiu, através de decreto-lei, as quotas de importação que vigoravam desde 1976; instituiu-se, através da Lei no.8.248 de 1991, um redutor de 88\% sobre a alíquota do imposto de Importação incidente sobre os produtos industrializados na ZFM, com projeto aprovado até março de 1991, excluindo porém os bens de informática, automóveis e outros produtos; através de DecretoLei, obrigou as empresas industriais locais a iniciarem, em 24 meses, a implantação de sistemas de qualidade baseados nas normas da seria 19.000 da ABNT ou a ISO 9.000. Novamente, mais algumas mudanças se tornam importantes, quando em dezembro de 1991, a Lei no. 8.387 dá nova redação ao Decreto-Lei no. 288 e todos os que os sucederam.
} 
ção de determinado produto (Garcia, 2004). A ordem era modernizar (com o livre acesso a insumos estrangeiros), buscar qualidade e produtividade, ganhar competitividade.

As empresas industriais eliminaram desperdícios, investiram em novas técnicas de gestão e qualificação de mão de obra, incorporaram novas tecnologias de processos, obtiveram significativa redução do custo final do produto, passando a competir no mercado interno em qualidade e preço com os produtos importados, e alcançando, muitas vezes, capacidade de competir no mercado externo

A diminuição dos preços dos produtos, especialmente, eletroeletrônicos, juntamente com a queda da inflação, impulsionado pelo Plano Real (1994), e o efeito da política cambial também, refletiu favoravelmente sobre a demanda, determinando o aumento dos níveis de produção e de faturamento de muitos produtos da Zona Franca de Manaus.

Com relação à origem dos insumos, no período entre 1992 e 1995, do total incorporado ao processo produtivo das indústrias da Zona Franca de Manaus de aproximadamente US $\$ 15$ bilhões, US $\$ 8,14$ bilhões foram comprados no mercado nacional e US\$ 6,61 bilhões no mercado externo. Do total dos insumos apenas nacionais, US $\$ 4,07$ bilhões foram adquiridos no parque local de componentes e US $\$$ 4,69 bilhões de outras regiões do país.

Ainda, a partir da década de 90, e apesar de um considerável crescimento relacionado ao faturamento das empresas, ao emprego de mão-de-obra, e outros indicadores, era preciso ampliar em larga escala os ganhos de competitividade do Pólo Industrial de Manaus, por meio da implantação de projetos de componentes chamados de "classe A"14, reduzindo os custos de transportes e gerando economias de aglomeração; ganhar economias de escala e otimizar o perfil da demanda da produção industrial; fortalecer a infra-estrutura física, institucional, industrial e de recursos humanos ${ }^{15}$.

\footnotetext{
14 Empresas que produzem bens vitais para suprir o mercado local (www.suframa.gov.br).

15 Em 1996, o Modelo ZFM tinha como prioridade/objetivo a consolidação da competitividade estrutural do seu parque industrial e a criação de alternativas de desenvolvimento para a Amazônia Ocidental - turismo ecológico, alimentos, fármacos e cosméticos buscando parcerias com órgãos governamentais, instituições de ensino e pesquisa, agencias de financiamento e empresas privadas. Nessa direção, a SUFRAMA definiu a sua participação no Programa de Ecologia Molecular para o Uso Sustentável da Biodiversidade da Amazônia PROBEM Amazônia, com a criação do Centro de Biotecnologia da Amazônia (CBA), no Distrito Industrial, e passou a incentivar pesquisas e aplicações que pudesse garantir o aproveitamento econômico e conservação da biodiversidade amazônica.
} 


\subsection{Mercado de trabalho, faturamento e aquisição de insumos}

Os incentivos fiscais, que ainda prevalecem atualmente, podem mais especificamente serem resumidos da seguinte forma: a) Federais - Imposto de Importação (II) - redução de $88 \%$ sobre os insumos destinados à industrialização ou proporcional ao valor agregado nacional quando se tratar de Bens de Informática; Importo sobre Produtos Industrializados (IPI) - Isento; Imposto sobre a Renda (IR) - redução de $75 \%$ do imposto sobre a renda e adicionais não restituíveis, exclusivamente para re-investimentos. Comum em toda a Amazônia Legal; Programa de Integração Social (PIS) e Financiamento da Seguridade Social (COFINS) - alíquota zero nas entradas e nas vendas internas inter-indústrias e de 3,65\% (com exceções) nas vendas de produtos acabados para o resto do país; e o Imposto de Exportação - IE; b) Estadual - Imposto sobre a Circulação de Mercadorias e Serviços (ICMS) - crédito estímulo entre $55 \%$ e $100 \%$. Em todos os casos as empresas são obrigadas a contribuir para fundos de financiamento ao ensino superior, turismo, $\mathrm{P} \& \mathrm{D}$ e às pequenas e microempresas.

Neste novo cenário, a SUFRAMA implantou uma política que integrasse três grandes vetores de ações essenciais (Machado et al., 2006): o adensamento das cadeias produtivas dos bens fabricados com incentivos em Manaus - viabilizando a formação de um significativo parque de fabricantes de insumos e componentes (estrangeiros ou nacionais) que integram as cadeias produtivas dos produtos considerados carro-chefe do PIM (televisores, telefones celulares, motocicletas, DVDs, aparelhos de som e outros); pesados esforços na promoção e investimento em Ciência, Tecnologia e Inovação (C,T\&I), inseridos como item regular da agenda institucional da SUFRAMA, e realizados em parceria com diversas instituições de pesquisa locais, públicas e privadas; a internacionalização da indústria local - adotando mecanismos de estímulos às exportações e de programas de promoção comercial e de cooperação internacional, integrados a um processo de interiorização dos resultados do desenvolvimento na Amazônia Ocidental - por meio de aproveitamento sustentável dos recursos naturais amazônicos e da aplicação dos recursos próprios da SUFRAMA, gerados a partir da arrecadação de sua Taxa de Serviços Administrativos (TSA).

A política de incentivos do Modelo da Zona Franca de Manaus atraiu para o PIM mais de quatrocentos e cinqüenta companhias dotadas de marcas conhecidas mundialmente, com impacto muito significativo sobre o PIB do estado e do município de Manaus.

Em 2005 a indústria de transformação contribuiu com 37,5\% do PIB do estado do Amazonas, sendo deste total, aproximadamente $82 \%$ referente à participação do município de Manaus. Isto tornou Manaus o município de maior 
DINIZ, M. J. T. et al. Inovação x eficiência: um estudo empírico para o Polo Industrial de Manaus...

PIB em toda Região Norte, com uma renda per capita superior a $\mathrm{R} \$ 10.000$. Além disso, o Valor Adicionado Bruto exclusivamente atribuído à indústria colocava Manaus em 2005 como o quarto município brasileiro em geração de riqueza a partir da indústria (Rivas et al., 2009).

Quanto ao mercado de trabalho, observa-se que a evolução da mão-de-obra (emprego formal), no período entre 1995 e 2004 para o estado do Amazonas, foi $55,13 \%$, superior ao do Brasil, que cresceu 32,2\% (Ministério do Trabalho/ CAGED, apud SUFRAMA, 2007).

No que diz respeito ao faturamento total das empresas situadas no PIM, no período de 1988 a 2006, houve um crescimento muito significativo. Neste período, o faturamento referente às vendas para o exterior foi o que mais cresceu - 2.388,17\% (Tabela 1). Embora, sua participação no faturamento total ainda representa um menor percentual $-5,1 \%$ em relação ao regional $19,2 \%$ e ao nacional $-75,7 \%$.

O grau de nacionalização ${ }^{16}$, originários no próprio PIM e de outros estados da federação girava, também, em torno de $50 \%$ em 2007 e, por sua vez o grau de regionalização ${ }^{17}$ atingiu, também em 2007, um índice de quase 30\% (Tabela 2). Em relação à aquisição de insumos, a origem da matéria-prima/componentes de todos os setores do PIM somando a origem regional e nacional, é de produção doméstica, como se viu acima, através dos dados sobre a nacionalização da produção. Entretanto, a participação de empresas estrangeiras no pólo de Manaus faz com que muitas empresas ainda tenham que importar bens intermediários para sua produção. Essas empresas compram equipamentos básicos e componentes de suas matrizes no exterior.

TABELA 1. FATURAMENTO E CRESCIMENTO DO PIM DE 1988 A 2006

\begin{tabular}{l|c|c|c|c}
\hline \multirow{2}{*}{ Anos } & \multicolumn{4}{|c}{ Faturamento e Crescimento em US\$ } \\
\cline { 2 - 5 } 1988 & Regional & Nacional & Exterior & \multicolumn{1}{c}{ Total } \\
\hline 2006 & 1.264 .012 .617 & 3.774 .911 .807 & 59.657 .143 & 5.098 .581 .567 \\
& 4.846 .557 .234 & 16.543 .354 .387 & 1.484 .373 .101 & 22.874 .284 .722 \\
$\begin{array}{l}\text { Total } \\
\text { período }\end{array}$ & 35.452 .341 .818 & 147.846 .288 .862 & 9.943 .890 .101 & 195.242 .521 .512 \\
$\begin{array}{l}\text { Cresc. no } \\
\text { período (\%) }\end{array}$ & 283,43 & 338,24 & $2.388,17$ & \\
\hline
\end{tabular}

FONTE: SUFRAMA, 2007. Elaboração dos autores.

16 Grau de Nacionalização - A relação entre o valor dos insumos nacionais sobre o total dos insumos adquiridos.

17 Grau de Regionalização - aquisição de insumos oriundos somente do PIM sobre o total das aquisições de insumos. 
Vale observar, que com relação ao Mercado Externo o saldo ao longo do período de 1988 e 2006, foi negativo, indicando uma dependência importante de insumos industriais importados nas empresas situadas no PIM. Todavia para o Mercado Nacional o saldo em todo o período é positivo, estando às exportações muito concentradas em aparelhos eletroeletrônicos.

O país de maior destino da produção do Polo são os Estados Unidos, entretanto, os países vizinhos da região Amazônica, em conjunto, equivalem mais do que os países desenvolvidos (Tabela 3).

TABELA 2. AQUISIÇÃO DE INSUMOS E FATURAMENTO SEGUNDO A ORIGEM (\%)

\begin{tabular}{|c|c|c|c|c|c|c|c|c|}
\hline \multirow[t]{2}{*}{ Anos } & \multicolumn{5}{|c|}{ Aquisição de Insumos } & \multicolumn{3}{|c|}{ Faturamento } \\
\hline & Regional & & Nacional & Exterior & & Regional & Nacional & Exterior \\
\hline 1988 & & 34,03 & 48,47 & & 17,51 & 24,79 & 74,04 & 1,17 \\
\hline 1989 & & 35,81 & 43,70 & & 20,48 & 24,06 & 75,06 & 0,88 \\
\hline 1990 & & 38,42 & 43,89 & & 17,69 & 21,62 & 77,65 & 0,74 \\
\hline 1991 & & 37,46 & 37,95 & & 24,59 & 22,50 & 76,46 & 1,04 \\
\hline 1992 & & 34,23 & 34,10 & & 31,67 & 17,92 & 79,54 & 2,53 \\
\hline 1993 & & 24,19 & 33,65 & & 42,17 & 14,61 & 83,92 & 1,47 \\
\hline 1994 & & 26,60 & 30,28 & & 43,12 & 16,39 & 82,31 & 1,30 \\
\hline 1995 & & 24,85 & 27,86 & & 47,29 & 18,62 & 80,52 & 0,86 \\
\hline 1996 & & 25,09 & 28,17 & & 46,74 & 18,96 & 80,24 & 0,79 \\
\hline 1997 & & 29,13 & 29,35 & & 41,51 & 17,19 & 81,54 & 1,28 \\
\hline 1998 & & 25,32 & 27,95 & & 46,73 & 16,07 & 81,64 & 2,29 \\
\hline 1999 & & 20,86 & 24,11 & & 55,03 & 15,40 & 79,40 & 5,21 \\
\hline 2000 & & 22,73 & 22,22 & & 55,05 & 17,33 & 75,54 & 7,14 \\
\hline 2001 & & 24,52 & 21,00 & & 54,48 & 18,43 & 72,49 & 9,08 \\
\hline 2002 & & 27,75 & 20,02 & & 52,23 & 17,69 & 71,05 & 11,27 \\
\hline 2003 & & 29,25 & 17,71 & & 53,04 & 18,13 & 70,23 & 11,63 \\
\hline 2004 & & 32,36 & 18,19 & & 49,45 & 20,76 & 71,47 & 7,77 \\
\hline 2005 & & 32,57 & 18,99 & & 48,44 & 20,89 & 68,45 & 10,66 \\
\hline 2006 & & 31,91 & 18,44 & & 49,65 & 21,19 & 72,32 & 6,49 \\
\hline
\end{tabular}

FONTE: SAP/CGPRO/COISE, SUFRAMA (2007). Elaboração dos autores.

TABELA 3. PRINCIPAIS DESTINOS DAS EXPORTAÇÕES - 2006 - U\$

\begin{tabular}{l|c|c}
\hline \multicolumn{1}{c|}{ Países } & Valores (mil) & \multicolumn{1}{c}{ (\%) } \\
\hline Estados Unidos & $376.889,00$ & 24.75 \\
Venezuela & $285.464,00$ & 18.75 \\
Argentina & $268.602,00$ & 17.64 \\
Colombia & $101.279,00$ & 6.65 \\
Chile & $64.090,00$ & 4.21 \\
México & $57.401,00$ & 3.77 \\
Alemanha & $46.671,00$ & 3.06 \\
Peru & $34.842,00$ & 2.29 \\
Jamaica & $22.472,00$ & 1.48 \\
Holanda & $17.024,00$ & 1.12 \\
\hline
\end{tabular}

FONTE: SUFRAMA, 2007. 


\subsection{Análise setorial do Polo Industrial de Manaus}

O setor Eletroeletrônico, que aqui é composto pelos subsetores Eletroeletrônicos Bens Finais, Componentes e Bens de Informática é o que tem a maior quantidade de trabalhadores e também o maior volume de investimentos. $\mathrm{O}$ investimento é em parte explicado pela entrada de firmas estrangeiras ou mesmo de filiais de firmas nacionais em todo o período considerado.

Entretanto vale considerar, que no que se refere à mão de obra, o maior crescimento se deu nos setores Mecânico, Metalúrgico e Químico, respectivamente. Os outros setores considerados com grandes volumes de investimentos são o Papel e Papelão e Termoplástico. Isso pode ser explicado pela necessidade de interação dos setores considerados no PIM.

Por unidade de emprego, os subsetores mais significativos são o mineral não metálico e o químico e os descartáveis (Tabela 4). 
DINIZ, M. J. T. et al. Inovação x eficiência: um estudo empírico para o Polo Industrial de Manaus...

TABELA 4. INDICADORES DE INVESTIMENTO E EMPREGO DOS SUBSETORES DO PÓLO INDUSTRIAL DE MANAUS - 2000 A 2006

\begin{tabular}{|c|c|c|c|c|c|c|c|}
\hline & \multicolumn{7}{|c|}{ Investimentos Totais em US $\$ 1,00$} \\
\hline Substores & 2000 & 2001 & 2002 & 2003 & 2004 & 2005 & 2006 \\
\hline Eletroeletrônico & 618.469 .101 & 754.705 .514 & 897.779 .059 & 1.320 .571 .944 & 1.611 .310 .467 & 2.014 .448 .660 & 2.260 .076 .051 \\
\hline Relojoeiro & 54.107 .136 & 50.535 .932 & 47.081 .864 & 65.025 .396 & 63.341 .962 & 63.556 .403 & 66.420 .870 \\
\hline Duas Rodas & 305.963 .851 & 288.044 .789 & 252.632 .929 & 348.882 .042 & 633.109 .628 & 941.236 .630 & 1.054 .682 .119 \\
\hline Termoplástico & 85.160 .512 & 89.022 .864 & 117.052.107 & 233.572.101 & 283.407.242 & 378.802 .911 & 459.737 .873 \\
\hline Bebidas & 10.581 .282 & 21.122.619 & 35.257 .414 & 48.882 .925 & 60.460 .011 & 27.172 .840 & 68.002 .663 \\
\hline Metalúrgico & 1.677 .539 & 54.531 .099 & 59.594 .571 & 94.989 .654 & 113.020 .983 & 146.649 .844 & 188.952 .798 \\
\hline Mecânico & 6.643 .208 & 26.475 .116 & 57.930 .098 & 121.258 .739 & 198.101 .973 & 191.902 .736 & 279.945 .317 \\
\hline Madeireiro & 24.085 .678 & 24.010 .097 & 15.384 .308 & 29.033 .117 & 33.364 .867 & 32.086 .486 & 49.128 .615 \\
\hline Papel e Papelão & 11.352 .728 & 9.947 .326 & 45.383 .208 & 61.196 .472 & 57.810 .886 & 55.366 .639 & 101.022 .832 \\
\hline Químico & 238.232 .700 & 348.073 .444 & 245.632 .290 & 347.127 .459 & 398.890 .536 & 528.314 .508 & 405.279 .890 \\
\hline Têxtil & 79.172 & - & 71.658 .248 & 91.850 .800 & 6.882 .228 & 5.603 .284 & 8.291 .650 \\
\hline Mineral Não Metálico & 210.045 & 181.021 .750 & 125.119 .725 & 155.406 .463 & 190.316 .574 & 209.513.198 & 186.865 .654 \\
\hline Ótico & 18.577 .740 & 17.098 .389 & 11.996 .982 & 15.651 .363 & 18.669 .414 & 23.474 .483 & 24.107 .777 \\
\hline Brinquedos & 93.354 & 1.997 .163 & 636.505 & 892.142 & 822.557 & 1.146 .585 & 799.511 \\
\hline Descartáveis & 144.829 .230 & 71.119 .446 & 69.371 .085 & 118.237 .160 & 190.688 .830 & 259.794 .476 & 292.492 .304 \\
\hline Diversos & 28.977 .905 & 25.904 .686 & 36.851 .833 & 53.726 .147 & 64.852 .077 & 80.065 .277 & 95.531 .807 \\
\hline \multirow[t]{2}{*}{ Total } & 1.549 .041 .181 & 1.963 .610 .234 & 2.089 .362 .226 & 3.106 .303 .924 & 3.925 .050 .235 & 5.129 .434 .052 & 5.541 .337 .732 \\
\hline & \multicolumn{7}{|c|}{ Emprego } \\
\hline Substores & 2000 & 2001 & 2002 & 2003 & 2004 & 2005 & 2006 \\
\hline Eletroeletrônico & 25.870 & 28.100 & 27.910 & 30.937 & 41.381 & 47.637 & 51.333 \\
\hline Relojoeiro & 1.407 & 1.456 & 1.469 & 1.468 & 1.442 & 1.368 & 1.386 \\
\hline Duas Rodas & 5.709 & 6.566 & 7.490 & 9.052 & 10.264 & 11.303 & 12.831 \\
\hline Termoplástico & 2.933 & 3.609 & 5.100 & 5.436 & 5.992 & 7.130 & 8.441 \\
\hline Bebidas & 928 & 1.105 & 1.166 & 1.248 & 1.437 & 1.448 & 1.808 \\
\hline Metalúrgico & 1.400 & 1.531 & 1.861 & 2.447 & 3.151 & 3.915 & 5.000 \\
\hline Mecânico & 435 & 505 & 2.066 & 2.912 & 3.511 & 3.606 & 3.857 \\
\hline Madeireiro & 2.391 & 2.182 & 1.956 & 1.652 & 1.935 & 1.897 & 1.163 \\
\hline Papel e Papelão & 874 & 1.113 & 1.167 & 1.371 & 1.724 & 1.940 & 2.084 \\
\hline Químico & 526 & 679 & 1.397 & 1.534 & 1.543 & 1.535 & 1.578 \\
\hline Têxtil & 64 & 470 & 484 & 533 & 644 & 640 & 598 \\
\hline Mineral Não Metálico & 650 & 554 & 556 & 563 & 588 & 614 & 526 \\
\hline Ótico & 1.049 & 1.121 & 393 & 400 & 456 & 495 & 514 \\
\hline Brinquedos & 175 & 464 & 322 & 287 & 178 & 84 & 33 \\
\hline Descartáveis & 1.577 & 1.734 & 1.475 & 1.616 & 1.710 & 1.870 & 2.471 \\
\hline Diversos & 4.017 & 3.570 & 3.000 & 3.135 & 3.425 & 3.742 & 4.798 \\
\hline Total & 50.005 & 54.759 & 57.812 & 64.591 & 79.381 & 89.224 & 98.421 \\
\hline Substores & \multicolumn{7}{|c|}{ Investimento por unidade de emprego } \\
\hline Eletroeletrônico & 23.907 & 26.858 & 32.167 & 42.686 & 38.938 & 42.287 & 44.028 \\
\hline Relojoeiro & 38.456 & 34.709 & 32.050 & 44.295 & 43.926 & 46.459 & 47.923 \\
\hline Duas Rodas & 53.593 & 43.869 & 33.729 & 38.542 & 61.683 & 83.273 & 82.198 \\
\hline Termoplástico & 29.035 & 24.667 & 22.951 & 42.968 & 47.298 & 53.128 & 54.465 \\
\hline Bebidas & 11.402 & 19.115 & 30.238 & 39.169 & 42.074 & 18.766 & 37.612 \\
\hline Metalúrgico & 1.198 & 35.618 & 32.023 & 38.819 & 35.868 & 37.458 & 37.791 \\
\hline Mecânico & 15.272 & 52.426 & 28.040 & 41.641 & 56.423 & 53.218 & 72.581 \\
\hline Made ireiro & 10.073 & 11.004 & 7.865 & 17.575 & 17.243 & 16.914 & 42.243 \\
\hline Papel e Papelão & 12.989 & 8.937 & 38.889 & 44.636 & 33.533 & 28.540 & 48.475 \\
\hline Químico & 452.914 & 512.627 & 175.828 & 226.289 & 258.516 & 344.179 & 256.831 \\
\hline Têxtil & 1.237 & - & 148.054 & 172.328 & 10.687 & 8.755 & 13.866 \\
\hline Mineral Não Metálico & 323 & 326.754 & 225.035 & 276.033 & 323.668 & 341.227 & 355.258 \\
\hline Ótico & 17.710 & 15.253 & 30.527 & 39.128 & 40.942 & 47.423 & 46.902 \\
\hline Brinquedos & 533 & 4.304 & 1.977 & 3.109 & 4.621 & 13.650 & 24.228 \\
\hline Descartáveis & 91.838 & 41.015 & 47.031 & 73.167 & 111.514 & 138.928 & 118.370 \\
\hline Diversos & 7.214 & 7.256 & 12.284 & 17.138 & 18.935 & 21.396 & 19.911 \\
\hline Total & 30.978 & 35.859 & 36.141 & 48.092 & 49.446 & 57.489 & 56.302 \\
\hline
\end{tabular}

FONTE: SUFRAMA (2008), Elaboração dos autores.

NOTA: $\left({ }^{*}\right)$ Em todas as colunas estão incluídos: Eletroeletrônico Componentes e Bens de Informática; $\left({ }^{* * * * *}\right)$ Composto pelos setores: Couros e Similares; Material de Limpeza; Produtos Alimentícios; Editorial e Gráfico; Mobiliário; Beneficiamento de borracha;Naval; Relojoeiros; Ótico; Brinquedos e Diversos; (1) Dados médios de Mão de obra efetiva + temporária+ terceirizada. 
Os Investimentos Líquidos Estrangeiros no PIM, no período considerado 2000 e 2006 - foram bastante significantes, chegando em 2006 a aproximadamente 3,1 bilhões de dólares, que envolveram 144 empresas de vários setores. Número considerável quando comparável as 613 empresas de diversos setores, instaladas no PIM até aquela data. Esses investimentos estrangeiros foram originários basicamente do Japão, EUA, Países Baixos, Coreia e França.

A importância relativa dos subsetores: Eletrônico e Duas Rodas fica evidenciado quando se analisa os dados da evolução do emprego e do faturamento ao longo do período de 1988 a 2006. Assim, em 1988 esses dois subsetores respondiam por cerca de 60\% do emprego total, passando para 65\% em 2006. Destaque para o aumento da participação relativa do subsetor Duas Rodas que passou de 5,6\% em 1988 para $13 \%$ em 2006. No que se refere ao faturamento em relação aos outros subsetores ele é consideravelmente superior aos demais, como pode ser evidenciado no Gráfico 1.

GRÁFICO 1. PARTICIPAÇÃO RELATIVA DOS SUBSETORES PRODUTIVOS DO PÓLO INDUSTRIAL DE MANAUS, SEGUNDO O FATURAMENTO EM ANOS SELECIONADOS - 1988, 1996 E 2006

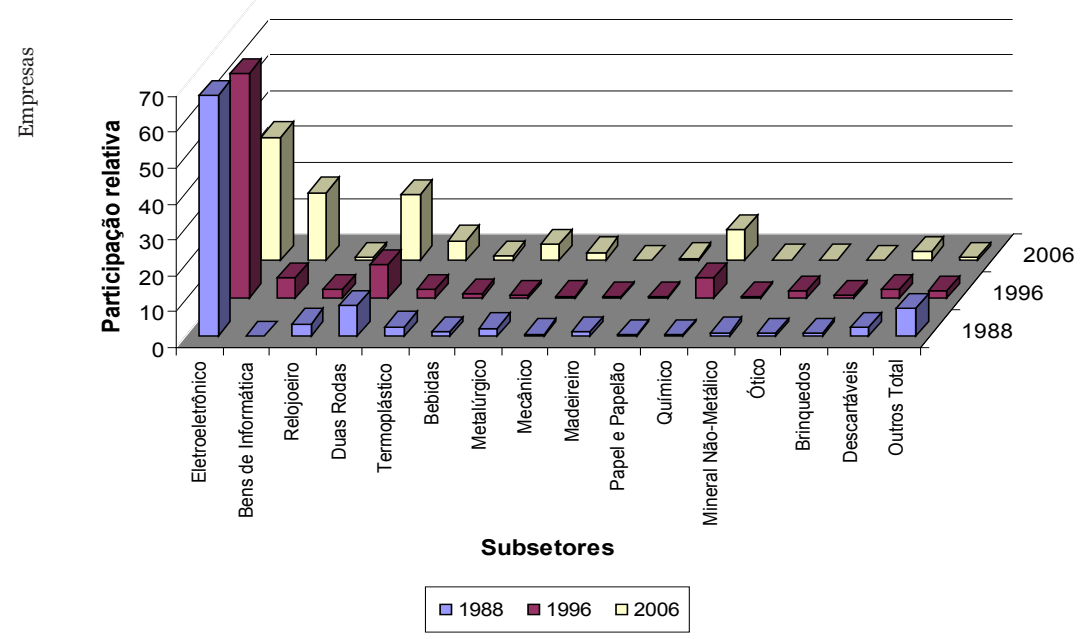

FONTE: Elaboração dos autores.

Abaixo, na Tabela 5, está retratado o "desempenho" inovativo das empresas situadas no estado do Amazonas, segundo a PINTEC em dois períodos 20012003 e 2003-2005, no qual se observa um número bastante expressivo e crescente de empresas que implantaram algum tipo de inovação, notadamente inovações de produto e processo, comparando os dois períodos. 
DINIZ, M. J. T. et al. Inovação x eficiência: um estudo empírico para o Polo Industrial de Manaus...

Além disso, a atividade inovadora concentrou-se na de fabricação de aparelhos e equipamentos de comunicações e artigos de borracha e plástico, ambos pertencentes às cadeias produtivas relacionadas ao subsetor de eletroeletrônico, em particular, do segmento relativo à produção de artigos de informática.

TABELA 5. ATIVIDADES INOVATIVAS DAS EMPRESAS DO ESTADO DO AMAZONAS, SEGUNDO A PINTEC - 2003 E 2005

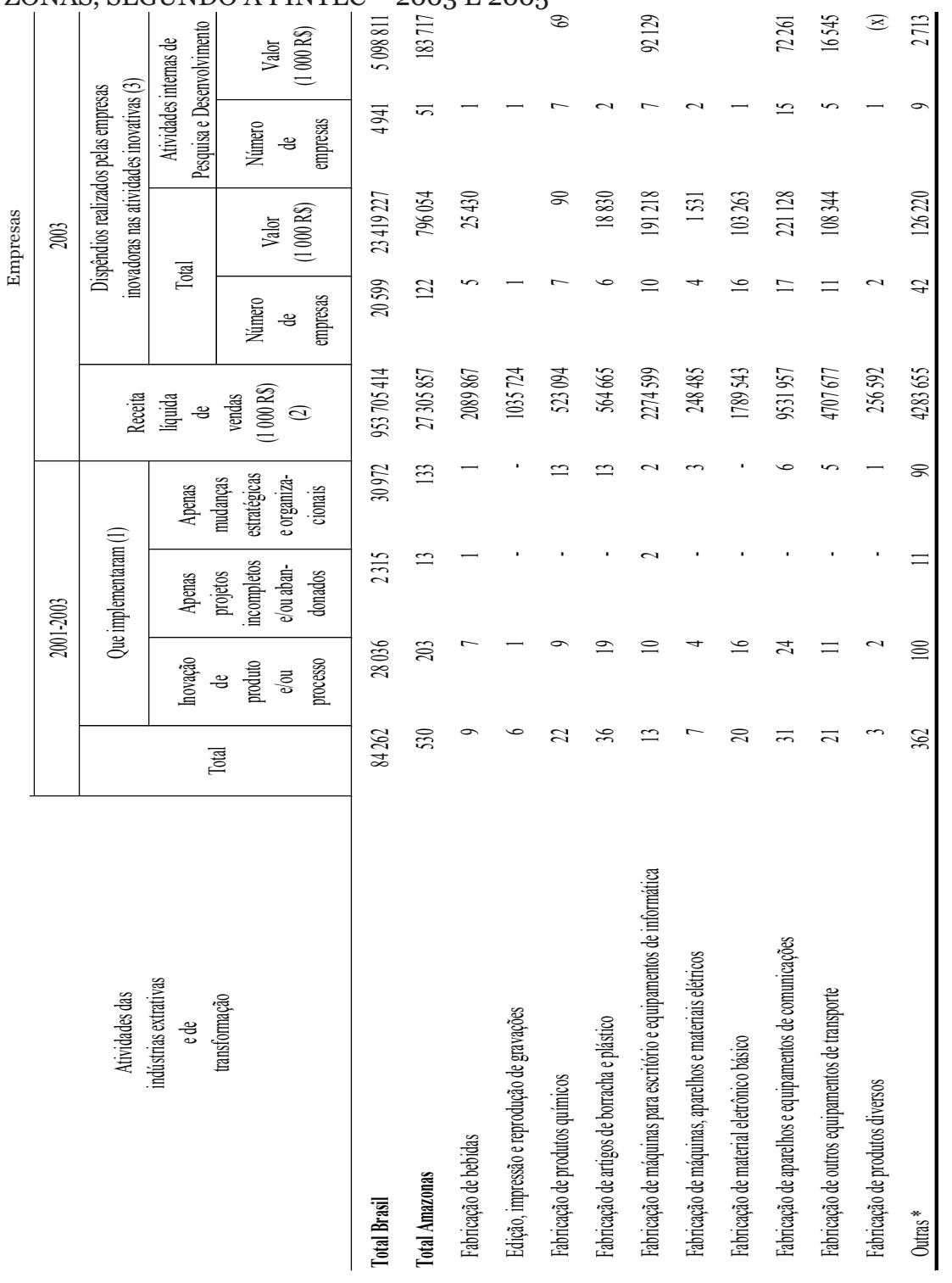


DINIZ, M. J. T. et al. Inovação x eficiência: um estudo empírico para o Polo Industrial de Manaus...

TABELA 5 (CONTINUAÇÃO). ATIVIDADES INOVATIVAS DAS EMPRESAS DO ESTADO DO AMAZONAS, SEGUNDO A PINTEC - 2003 E 2005

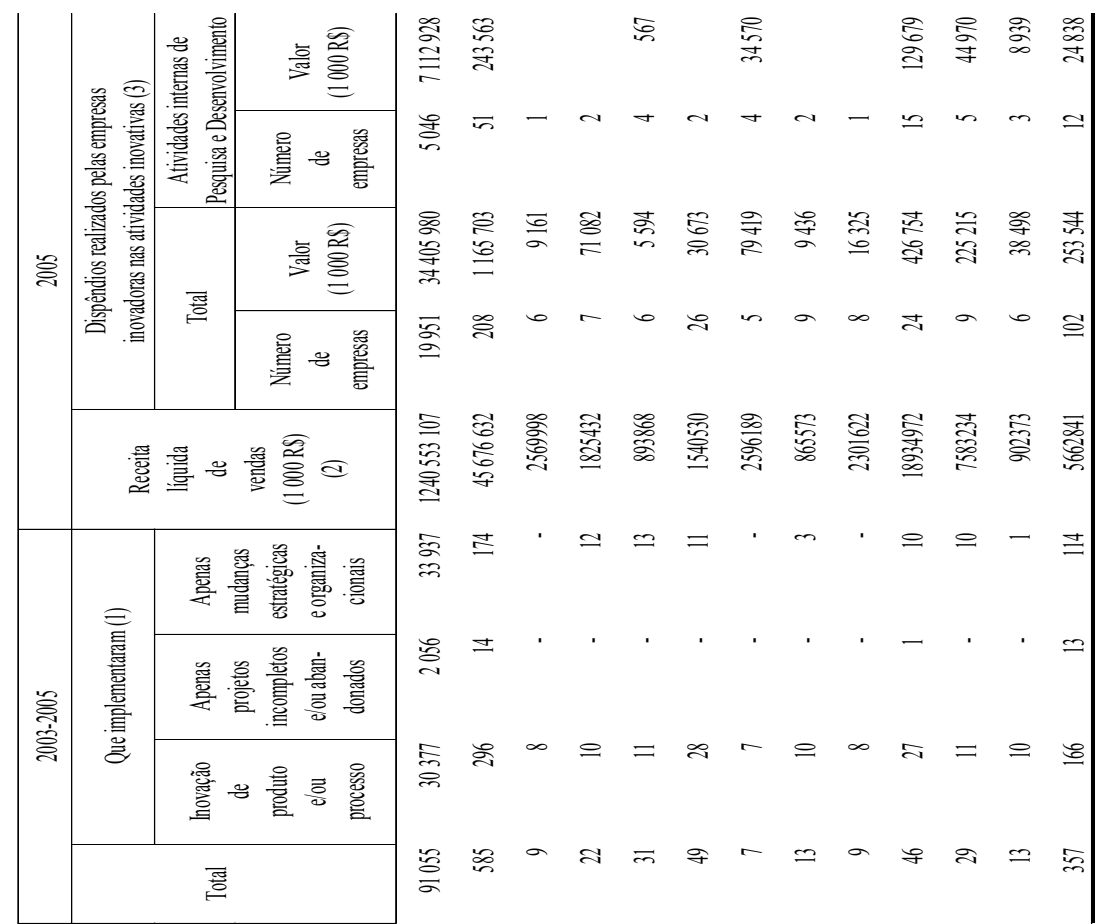

Fonte: IBGE, Diretoria de Pesquisas, Coordenação de Indústria, Pesquisa Industrial de Inovação Tecnológica 2003 e Pesquisa de Inovação Tecnológica 2005.

NOTA: (1) Nos períodos pesquisados, foram consideradas as empresas que implementaram produto e/ou processo tecnologicamente novo ou substancialmente aprimorado, que desenvolveram projetos que foram abandonados ou ficaram incompletos, e que realizaram mudanças organizacionais; (2) Receita líquida de vendas de produtos e serviços estimada a partir dos dados das amostras da Pesquisa Industrial Anual Empresa 2003 e 2005; (3) Foram consideradas as empresas que implementaram produto e/ou processo tecnologicamente novo ou substancialmente aprimorado. 


\section{Evidência empíricas sobre a eficiência das empresas - fronteira de produção estocástica}

\subsection{Estimação}

O procedimento adotado reside na utilização do método paramétrico conhecido como análise de fronteira estocástica de produção. Este método foi proposto inicialmente por Aigner, Lovell \& Schmidt (1977) e Meusen \& Broeck (1977). Na literatura pertinente, existe um grande número de estudos sobre a evolução da estimação de fronteiras de eficiência, entre esses, citam-se os devidos a Jondrow et al. (1982), Tulkens (1993), Banker (1996) e Souza; Alves \& Ávila (1997), tratando tanto de fronteiras paramétricas como nãoparamétricas. Paralelamente, as contribuições de Forsund, Lovell \& Schmidt (1980), Schmidt (1986), Bauer (1990), Battese (1992), Greene (1993), Battese \& Coelli (1995) permitiram o aprimoramento do método, possibilitando sua implementação com dados em painel e com a incorporação da modelagem do componente de ineficiência técnica de produção.

Uma das vantagens do método paramétrico reside na incorporação, além dos distúrbios aleatórios relativo à função de produção, de efeitos de ineficiência técnica ao contrário dos métodos não paramétricos, que atribuem à ineficiência técnica os desvios do produto observado em relação ao produto potencial (Marinho; Bittencourt, 2007).

Mas, por outro lado, o referido método de fronteira estocástica requer a especificação de uma forma funcional da fronteira de produção e o indispensável estabelecimento de hipóteses distribucionais sobre os componentes dos distúrbios e da ineficiência técnica.

Utilizando dados em painel para uma amostra de 132 empresas ${ }^{18}$ localizadas no Polo Industrial de Manaus - PIM, a forma funcional da fronteira estocástica foi determinada por meio de um teste de adequação (teste de máxima verossimilhança). Testou-se a hipótese nula de uma fronteira translog contra a alternativa de uma Cobb-Douglas. Em face do resultado do teste, adotou-se a função ${ }^{19}$ de fronteira de produção Cobb-Douglas especificada na forma:

$\ln$ FatTotal $=\alpha_{i}+\beta_{1} \ln$ trab $_{i t}+\beta_{2} \ln$ capital $_{i t}+\beta_{3} \ln$ insumo $_{i t}+\beta_{4}$ inovamb $_{+}+$
$\beta_{4}$ custicms $_{i t}+\beta_{5}$ exigam $_{i t}+\beta_{6}$ medcon $_{i t}+\beta_{7}$ inovprod $_{i t}+\beta_{8}$ inovproc $_{i t}+\varepsilon_{i t}$

18 Diferente das seções anteriores, só foram consideradas na amostra as empresas que iniciaram suas atividades pelo menos a partir de 2004, o que representou um corte de 19 empresas.

19 As variáveis utilizadas estão descritas na seção seguinte. 
DINIZ, M. J. T. et al. Inovação x eficiência: um estudo empírico para o Polo Industrial de Manaus...

$$
\varepsilon_{\mathrm{it}}=v_{i t}-u_{i t}
$$

Vale destacar que foi usado como variável dependente o faturamento total das empresas. Os parâmetros $\alpha_{i}$ incorporam ao modelo os efeitos fixos com o objetivo de capturar heterogeneidades não observadas na amostra, principalmente relacionadas às diferenças iniciais nos níveis tecnológicos. $\varepsilon_{\mathrm{it}}$ corresponde ao termo do erro composto, onde a variável $v_{i t}$ representa os distúrbios aleatórios da função de produção que, por hipótese, segue uma distribuição normal com média zero e variância constante $\sigma^{2}{ }_{v}$ e o termo $u_{i t}$, representando a ineficiência técnica de produção, segue uma distribuição half-normal, com média zero e variância $\sigma^{2}{ }^{2}$. Os parâmetros $\alpha_{i}$ e $\beta_{i}$, associados às variáveis acima descritas, foram estimados econometricamente.

Assim, a função distribuição do erro composto é dada por:

$$
f\left(\varepsilon_{i}\right)=\frac{\sqrt{2}}{\sigma_{u}} \sqrt{\pi}\left[1-F\left(\varepsilon_{i} \lambda \sigma^{-1}\right)\right] \exp \left(-\frac{\varepsilon_{i}^{2}}{2 \sigma^{2}}\right)
$$

Onde $\sigma^{2}=\sigma^{2}{ }_{u}+\sigma_{v}^{2} ; \lambda=\sigma_{u} / \sigma_{v}$ e $F(*)$ é a função de distribuição acumulada da normal padrão. A função log likelihood será, então:

$$
\ln L\left(y / \beta, \lambda, \sigma^{2}\right)=N \ln \frac{\sqrt{2}}{\sqrt{\pi}}+N \ln \sigma^{-1}+\sum_{i=1}^{N} \ln \left[1-F\left(\varepsilon_{i} \gamma \sigma^{-1}\right)\right]-\frac{1}{2 \sigma^{2}} \sum_{i=1}^{N} \varepsilon_{i}^{2}(4)
$$

Utilizando o método proposto por Jondrow et al. (1982), onde se considera o valor esperado de $u_{i}$ condicional a $\varepsilon_{\mathrm{i}}$, em que $v_{i}$ tem distribuição normal e $u_{i}$ tem distribuição half-normal, é possível estimar os índices de eficiência de cada empresa, com base na equação:

$$
E\left(u_{i} / \varepsilon_{i}\right)=\mu_{0}+\sigma \cdot \frac{f(-\mu . / \sigma .)}{1-F(-\mu . / \sigma .)}
$$

Onde $f$ e $F$ são a função densidade e função distribuição acumulada da normal, respectivamente, $-\left(\mu_{\bullet} / \sigma_{\bullet}\right)=\varepsilon_{i} \lambda \sigma, \sigma^{2}=\sigma^{2}{ }_{u}+\sigma^{2}{ }_{v}, \sigma^{2} .=\sigma^{2}{ }_{u} \sigma^{2}{ }_{v} / \sigma^{2} ; \lambda=\sigma_{u} / \sigma_{v}$.

Uma vez obtidos os valores da distribuição de $u_{i}$, basta tomar a exponencial, $\exp \left[-E\left(u_{i} / \varepsilon_{i}\right)\right]$, e estimar a eficiência técnica de cada empresa, que estará situada no intervalo [0,1], com o representando completa ineficiência e 1 plena eficiência. 
Os dados utilizados compreenderam dois níveis: dados secundários obtidos junto a Superintendência da Zona Franca de Manaus (SUFRAMA) no período de 2000 a 2006, e que se referem aos indicadores econômicos de desempenho das empresas; e primários - coletados através da aplicação de um questionário a uma amostra de 132 empresas PIM cadastradas nessa Instituição no ano de 2006. No primeiro caso referem-se aos valores/quantidades das empresas relativas ao faturamento, $\mathrm{ICMS}^{20}$ recolhido, despesas com insumos, investimento realizado, mão-de-obra direta empregada. No segundo caso, incluemse informações qualitativas referentes a se empresa realizou inovações de produto, processo, ambientais, ou se atendeu as exigências ambientais. Para efeito do cálculo do grau de concentração da indústria utilizou-se o índice de Hirschman-Herfindahl ajustado.

\subsection{Resultados}

Inicialmente foi realizado um teste estatístico relativo à forma funcional mais adequada a ser utilizada ${ }^{21}$. $\mathrm{O}$ resultado do referido teste indicou que a forma funcional mais adequada seria a função de produção do tipo CobbDouglas $^{22}$.

Com relação aos resultados da fronteira estocástica, pode-se observar na Tabela 5 que os coeficientes significantes estatisticamente, no nível de $5 \%$ foram: o logaritmo do trabalho (lntrab), o logaritmo do capital físico (lncapital), o logaritmo do insumo total ${ }^{23}$ (lninsumo), o custo com ICMS (custicms), a medida de concentração da indústria (medconc), a variável que representa as inovações em processo (inovproc) e a variável que representa as inovações ambientais (inovamb). Já as variáveis exigência ambiental (exigam) e inovação em produto (inovprod) não foram significantes.

20 O ICMS é um Imposto sobre Circulação de Mercadorias e Prestação de Serviços e por isso se apresenta como um custo para empresa. No caso do Pólo Industrial de Manaus, um dos incentivos concedidos pela Suframa é exatamente o valor adotado do Imposto sobre Circulação de Mercadoria - ICMS -, para cada empresa, a depender do tipo de produto produzido e dos insumos importados. À medida que a empresa aumenta sua produção (concomitante ao aumento na aquisição de insumos) e conseqüentemente suas vendas o valor do ICMS recolhido torna-se menor, e como num círculo virtuoso a empresa tem condição de expandir ainda mais sua produção.

21 O teste tem a finalidade de se verificar a consistência de hipóteses específicas relacionadas à fronteira de produção estocástica. Especificamente, trata-se do teste de adequação da forma funcional Translog relativamente à forma funcional mais restritiva Cobb-Douglas. Assim, testa-se a hipótese de que todos os coeficientes de segunda ordem e os coeficientes dos produtos cruzados são todos iguais a zero na especificação Translog. 22 O valor da razão de verossimilhança estimado foi de 47,75, que é inferior ao valor crítico da estatística $\chi^{2}{ }_{(36)}$ com nível de significância de 5\%, obtido em Kodde \& Palm (1986, p. 1246). Com isso, rejeita-se a especificação na forma de uma função Translog em favor do modelo Cobb-Douglas.

23 Aqui se considera o somatório do valor dos insumos adquiridos localmente, nacionalmente e internacionalmente. 
Com relação à insignificância estatística destas duas últimas variáveis é importante destacar o seguinte. A exigência ambiental funciona como um constrangimento externo à empresa, de tal sorte que o seu cumprimento não necessariamente ocorre a partir da introdução de soluções internas, que tragam resultados mais eficientes para as mesmas. Assim, por exemplo, a construção de aterros industriais, pode ser suficiente para atender uma dada regulamentação ambiental, mas só seria mais eficiente, se parte da energia consumida pela empresa pudesse ser originária do aproveitamento do gás metano do aterro. Por outro lado, a inovação de produto representou um percentual pouco expressivo entre as empresas que inovaram no período, o que pode ser um fator determinante para sua não significância em explicar a eficiência das empresas.

Em relação à eficiência, a estimativa do parâmetro lambda $(\lambda)$ - que mede a variabilidade das duas fontes de erro, o distúrbio ruído branco e o erro unilateral - apresentou um valor superior a unidade; 1,058 ; o que indica que a maior parte da variabilidade na produção advém da ineficiência técnica e não de fatores aleatórios. Ou seja, reduzindo a ineficiência técnica, obtém-se melhores resultados quanto à produção e seu valor.

TABELA 6. RESULTADOS DAS ESTIMATIVAS DA FUNÇÃO DE FRONTEIRA ESTOCÁSTICA DE PRODUÇÃO, PÓLO INDUSTRIAL DE MANAUS - 2001-2006

\begin{tabular}{l|c|c}
\hline \multicolumn{1}{c|}{ Parâmetros/Variáveis } & Coeficientes & Desvio-padrão \\
\hline lntrab & $0,2722^{*}$ & 0,0298 \\
lncapital & $0,0605^{*}$ & 0,0149 \\
lninsumo & $0,6437^{*}$ & 0,0184 \\
Exigam & 0,0030 & 0,0672 \\
Inovamb & $0,2339^{*}$ & 0,0656 \\
Custicms & $3,07 \mathrm{e}^{*}-08^{*}$ & $7,29 \mathrm{e}-09$ \\
Medconc & $0,0036^{*}$ & 0,0013 \\
Inovprod & $-0,1020$ & 0,0905 \\
Inovproc & $0,2023^{*}$ & 0,0866 \\
Constante & $4,37691^{*}$ & 0,2925 \\
$\sigma^{2}{ }^{2}$ & 0,5642 & \\
$\sigma^{2}{ }_{u}$ & 0,5972 & \\
$\lambda$ & 1,058 & \\
Log da função de verossimilhança & $-515,62$ & \\
\hline
\end{tabular}

FONTE: Elaboração dos autores.

NOTA: * Significante ao nível de $5 \%$.

Os escores de eficiência obtidos com a estimação da fronteira de produção estocástica permite fazer comparações entre as empresas mais e menos eficientes no ano de interesse, bem como entre as empresas mais eficientes entre dois pontos no tempo. 
Considerando o primeiro cenário, que trata da diferença entre as empresas mais eficientes e as menos eficientes no ano de 2006, conforme a Tabela 8 pode-se observar que não existe uma concentração de empresas de nenhum subsetor específico, tanto no grupo das empresas mais eficientes quanto no grupo das empresas menos eficientes. Pode-se observar também, por exemplo, que o grupo de empresas mais eficientes em 2006 possui um faturamento anual médio de $\mathrm{R} \$ 313.957 .600,30$ enquanto o grupo menos eficiente possui um faturamento anual médio de apenas $\mathrm{R} \$ 7.267 .760,10$, o que mostra uma diferença exorbitante. Já quando se observa a mão-de-obra empregada, o grupo mais eficiente emprega em média 69 pessoas enquanto que o outro grupo emprega 123 pessoas. Outra variável de destaque entre os grupos é o índice de concentração industrial, onde o grupo mais eficiente apresentouse mais concentrado, 0,10 e 0,09 , respectivamente. No que tange a questão da inovação tanto em produto quanto em processo, o grupo menos eficiente apresentou um percentual maior de empresas que utilizaram de tais recursos; entretanto, para o grupo de empresas mais eficientes, observa-se um percentual de participação maior, tanto na inovação ambiental quanto na exigência ambiental, $70 \%$ e $100 \%$ respectivamente.

Já no segundo cenário, quando a análise se concentra na diferença entre as empresas mais eficientes entre os anos de 2001 e 2006 (ano inicial e final da análise, respectivamente), observa-se, como no cenário anterior, que não existe uma concentração de empresas de nenhum dos pólos em nenhum dos anos da análise, embora o Pólo Termoplástico se destaque no ano de 2001. É possível observar, também, em 2006, que as empresas utilizam menos mão-de-obra que no ano de 2001, mas utilizam mais capital físico, o que caracteriza uma maior intensificação em capital ao longo do período. Vale destacar, também, que em 2006 as empresas mais eficientes apresentaram um índice de concentração menor que em 2001, bem como apresentaram uma maior participação em atividades relacionada à inovação em produto, inovação ambiental e em exigência ambiental (Tabela 8).

Portanto, os resultados permitem concluir, tanto na análise para o ano de 2006 quanto na análise entre os anos de 2001 e 2006, que as empresas que vêem cumprindo com as normas ambientais ao longo do período analisado têm conseguido obter um desempenho mais satisfatório, em termos de eficiência - aumentando seu faturamento (o que pode se deduzir seu market-share). 
DINIZ, M. J. T. et al. Inovação x eficiência: um estudo empírico para o Polo Industrial de Manaus...

TABELA 7 - DADOS REFERENTES ÀS FIRMAS MAIS EFICIENTES VS MENOS EFICIENTES NO ANO DE 2006
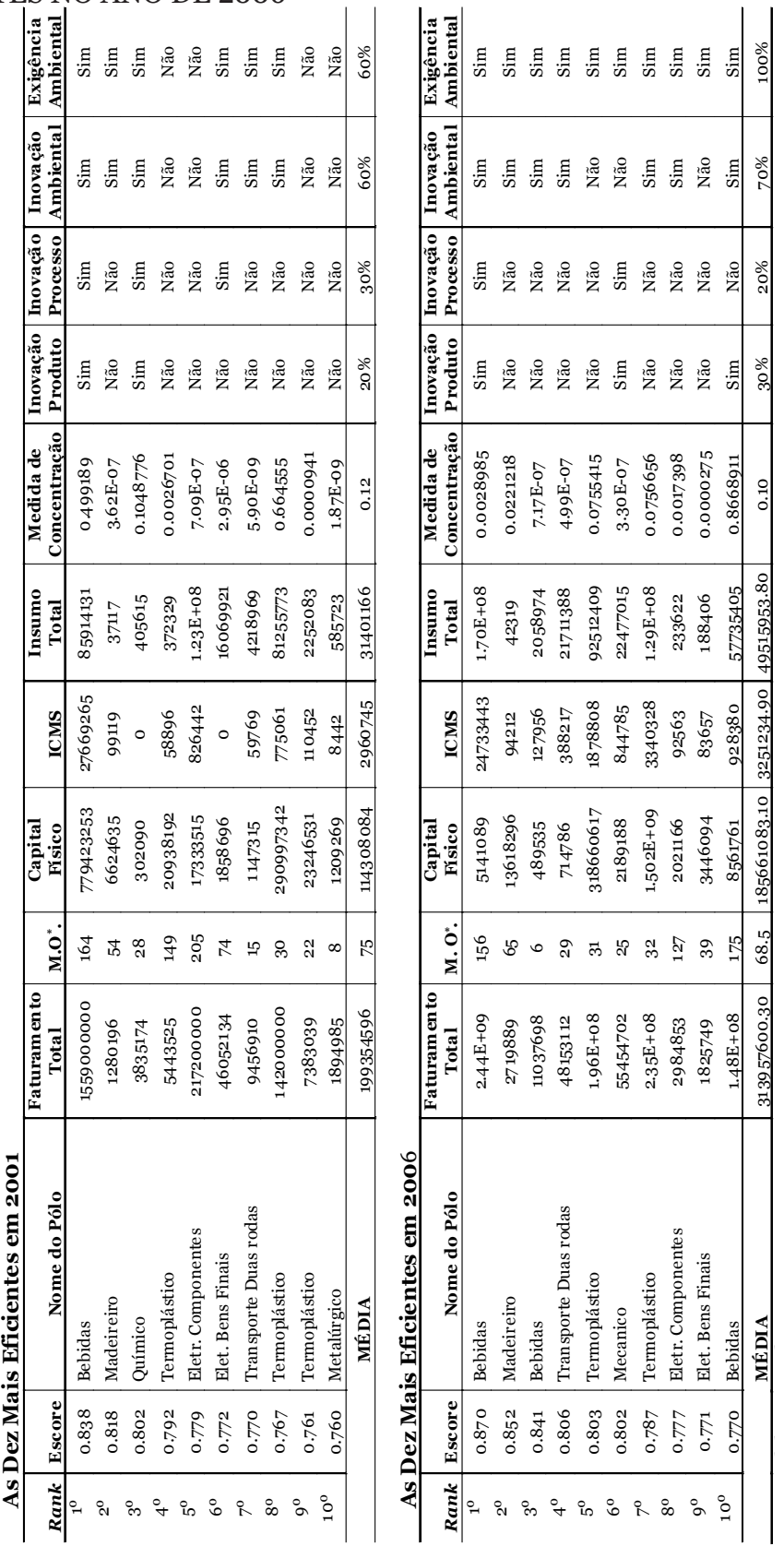

FONTE: Elaboração dos autores. NOTA: *M. O. = Mão de obra. 


\section{Considerações finais}

O artigo teve como principal objetivo analisar o processo de adoção de introdução de inovações pelas empresas situadas no PIM no período recente, por meio da análise de seus impactos na eficiência dessas empresas. Utilizou-se, para tanto, a técnica paramétrica de fronteira estocástica, bem como dados primários e secundários, para o período de 2000 a 2006.

Esse trabalho foi embasado em dois pressupostos teóricos básicos descritos acima da teoria da Organização Industrial, dentro da abordagem Evolucionária ${ }^{24}$ (Nelson;Winter, 1982; Dosi, 2006), corroborou sua hipótese de influência no desempenho da empresa, no caso, quanto a sua eficiência.

Assim, os resultados da fronteira estocástica mostraram que além das proxies para trabalho, capital físico, da variável representante do custo com ICMS, da medida de concentração da indústria, as variáveis inovações em processo e inovações ambientais apresentaram-se de forma significantes na explicação do faturamento das empresas no período de referência. Entretanto, as variáveis exigência ambiental e inovação em produto não o foram. Com relação à eficiência, os resultados apontaram que a maior parte da variabilidade na produção advém da ineficiência técnica e não de fatores aleatórios; ou seja, reduzindo a ineficiência técnica das empresas pode-se obter melhores resultados quanto à produção e seu valor.

Ainda com relação aos resultados do modelo de fronteira estocástica, foram elaborados dois cenários comparando-se as empresas a partir dos escores de eficiência estimados. No primeiro cenário - que compara as dez empresas mais eficientes com as dez empresas menos eficientes no ano de 2006 - observa-se que as dez empresas mais eficientes atendiam as exigências ambientais vigentes na legislação nacional e/ou regional e sete delas faziam algum tipo de inovação ambiental, diferentemente das empresas menos eficientes em que apenas oito delas atendiam as exigência ambientais e apenas cinco faziam algum tipo de inovação ambiental. Observa-se, também, que o faturamento médio do grupo das dez empresas mais eficientes é cerca de 40 (quarenta) vezes superior ao faturamento médio do grupo das dez empresas menos eficientes.

Já no segundo cenário - que compara as dez empresas mais eficientes no ano de 2001 com as dez empresas mais eficientes no ano de 2006 - um importante resultado diz respeito ao fato de que todas as empresas em 2006 passaram a atender as exigências ambientais vigentes na legislação nacional e/ou regional, diferentemente do ano de $2001 \mathrm{em}$ que apenas seis empresas atendiam as referidas exigências. Em relação às inovações ambientais, os resultados também indicam que ocorreu uma melhora, embora pequena, em que no ano

24 A Teoria Evolucionária toma como preceitos básicos a Teoria Schumpeteriana em sua interpretação do processo de mudança técnica (Ruttan, 1997). 
de 2001 apenas seis empresas faziam algum tipo de inovação ambiental e em 2006 passaram a ser sete empresas.

Portanto, os resultados permitem concluir, que as empresas que vêem adotando técnicas produtivas mais limpas e, assim fazendo inovações ambientais da forma explicitada no texto, no período analisado, têm conseguido obter um desempenho mais satisfatório, em termos de eficiência - aumentando seu faturamento (o que pode se deduzir de seu market-share).

\section{Referências}

AIGNER, D.J.; CHU, S. F. (1968). On estimating the industry production function. American Economic Review, v. 58, p. 826-839.

AIGNER, D. J.; LOVELLl, C. A. K. SCHMIDT, P. (1977). Formulation and estimation of stochastic frontier production functions models. Journal of Econometrics, v. 6, p. 21-37.

BANKER, R. D. (1996). Hypothesis tests using data envelopment analysis. The Journal of Productivity Analysis, v. 7, p. 138-158.

BATTESE, G. E. (1992). Frontier production function and technical efficiency: a survey of empirical applications in agricultural economics. Agricultural Economics, v. 7, p. 185-208.

BATTESE, G. E.; COELLI, T. J. (1995). A model for technical inefficiency effects in stochastic frontier production functions for panel data. Empirical Economics, 20, p. 325-332, 1995.

BAUER, P. W. (1990). Recent developments in the econometric estimation of frontiers. Journal of Econometrics, v. 46, p. 39-56.

BELL, M.; PAVITT, K. (1993). Technological accumulation and industrial growth: contrast between developed and developing countries. Industrial and Corporate Change, v. 2, n.2.

CIMOLI, M.; DOSI, G.; STIGLITZ,J.E. (2008). The political economy of capabilities accumulation: the Past and Future of Policies for Industrial Development. Laboratory of Economics and Management Sant'Anna School of Advanced Studies - LEM. Working Paper Series. July 2008/15.

DASGUPTA, S.; HETTIGE, H.; WHEELER, D. What improves environmental compliance: evidence from Mexican industry. Journal of Environmental Economics and Management, [S.1.], v. 39, p 23-48, 2000.

DOSI, Giovanni. (1982). Technological paradigms and technological trajectories. A Sugested interpretation of the determinants and directions of technical change. Research Policy 11. p. 147-162. 
DOSI, Giovanni. (1991). Una Reconsideración de las condiciones y los modelos del desarrollo. Una perspectiva "Evolucionista" de la innovación, el comercio y el crecimento. Mexico: Pensamento Iberoamericano. [S. I], n. 20, p. $167-191$.

DOSI, Giovanni. (2006). Mudança técnica e transformação industrial: a teoria e uma aplicação à industria dos semicondutores. Tradução: Carlos D. Szlak. Campinas, SP: Editora da Unicamp, 2006.

DOSI, G.; CIMOLI, M. (1992). Tecnologia y Desarrollo. Algunas consideraciones sobre los recientes avances en la economia de la innovación. IN:URANGA, M. G.; PADRON, M.S. \& PUERTA, Enrique de la (compiladores), Madrid: Economia Critica, 1992.

ESTY, D. C.; WINSTON A. S. (2008). O verde que vale ouro. Tradução Ana Beatriz Rodrigues. Rio de Janeiro: Elsevier.

FÄRE, Rolf; GROSSKOPF, Shawna; NORRIS, Mary; ZHANG, Zhongyang. (1994). Productivity growth, technical progress and efficiency change in industrialized countries. The American Economic Review, vol. 84, N. 1, p. 66-83.

FREEMAN, Christopher (1994). The economics of technical change: critical survey. Cambridge Journal of Economics, 18, p. 463-514.

FREEMAN, Christopher; SOETE, Luc. (2008). A economia da inovação industrial. Tradução: André Luiz Sica de Campos e Janaina de Oliveira Pamplona da Costa. Campinas-SP: UNICAMP.

FORSUND, F. R.; LOVELL, C. A. K.; SCHMIDT, P. (1980). A survey of frontier productivity functions and their relationship to efficiency measurement. Journal of Econometrics, v. 13, p. 5-25.

FURTADO, A. (Coord.), Capacitação Tecnológica, Competitividade e Política Industrial: uma abordagem setorial e por empresas líderes. Brasília: Texto para Discussão ${ }^{0}$ 398, IPEA, 1994.

GARCIA, E. (2004). Zona Franca de Manaus: história, conquistas e desafios. Manaus: Norma/SUFRAMA.

GRAY, W.B.; DEILY, M.E. (1996). Compliance and Enforcement: Air Polution regulation in U. S. steel industry. Journal of Environmental Economics and Management. v. 31, p. $96-111$.

GREEN, W. I. I. (1993). The econometric approach to efficiency analysis. In: Fried, H. O.; Lovell, C. A. K.; Schmidt, S. S. (eds.), The measurement of productivity efficiency: techniques and applications. New York: Oxford University Press, p. 68-119.

JONDROW, J. et al. (1982). On the estimation of technical inefficiency. Journal of Econometrics, v. 19, p. 233-238. 
KUMBHAKAR, Subal e LOVELL, C. A. Knox (2000). Stochastic frontier analysis. Cambridge: Cambridge Press.

LALL, Sanjaya (2005). A mudança tecnológica e a industrialização nas economias de industrialização da Ásia: conquistas e desafios. In: KIM, L; NELSON, R. R. (org.). Tecnologia, aprendizado e inovação: as experiências das economias de industrialização recente. Campinas-SP: UNICAMP.

LASZLO, Chris (2007). A empresa sustentável. Tradução Rui Alberto Pacheco. Lisboa-Portugal: Insituto PIAGET.

LAVILLE, Élisabeth. A empresa verde. São Paulo: Õte, 2009.

MACHADO, J. A. C. et al. (2006). Metamorfoses do modelo Zona Franca de Manaus: desafios à pesquisa e ao planejamento do desenvolvimento regional. In: SHERER, E.; OLIVEIRA, J. A. (org.). Amazônia políticas públicas e diversidade cultural. Rio de Janeiro: Garamond, p. 16-23.

MARINHO, Emerson; ATALIBA, Flávio e LIMA, Francisco. (2002). Produtividade, variação tecnológica e variação de eficiência técnica das regiões e estados brasileiros. Estudos Econômicos, São Paulo, vol. 32, n. 2, p. 367-407.

MARINHO, Emerson e BITTENOURT, Almir. (2007). Produtividade e crescimento econômico na America Latina: a abordagem da fronteira de produção estocástica. Estudos Econômicos, São Paulo, vol. 37, p. 5-33.

MEEUSEN, W.; VAN DEN BROECK, J. (1977). Efficiency estimation from Cobb-Douglas production functions with composed error. International Economic Review, v. 18, n. 2, p. 435-444, June, 1977.

NELSON, R. R.; WINTER, S. G. (1982). An evolutionary theory of economic change. Cambridge, Mass.: Harvard University Press.

PAVITT, K. Sectoral patterns of technical change. (1984). Research policy, 13, p.343-373.

RIVAS, A.; MOTA, J. A.; MACHADO, J. A. C. (org.) (2009). Instrumentos econômicos para a proteção da Amazônia: a experiência do Pólo Industrial de Manaus, Curitiba: CRV, Piatam Instituto.

ROSENBERG, N. (2006). Por dentro da caixa preta: tecnologia e economia. Campinas: UNICAMP.

RUTTAN, Vernon W. (1997). Induced innovation, evolutionary theory and path dependence: source of technical change. The Economic Journal, 107 (September), p. 1520-1529.

SOUZA, G. S.; ALVES, E.; ÁVILA, A. F. D. (1997). Produtividade e eficiência relativa de produção em sistemas de produção de pesquisa agropecuária. Revista Brasileira de Economia, v. 51, n. 3, p.281-307. 
STERN, N. The Economics of Climate Change: The Stern Review. Cambridge University 2007.

STIGLITZ, J. E. (1997). Market Failures, public goods, and externalities. In: MALINVAUD, E. (ed). Development strategy and market economy. Oxford: Oxford University Press.

SUFRAMA (2008). URL: http://www.suframa.gov.br/modelozfm_ind_indicadores.cfm.

SUFRAMA/SAP/CGPRO/COISE. Indicadores de desempenho do Pólo Industrial de Manaus, 1988/2007.

THOMAS, Janet; CALLAN, Scott J. Environmental Economics: applications, policy and theory. USA: CENCAGE Learning Inc, 2007.

TEECE, David J. (2005). As aptidões das empresas e o desenvolvimento econômico: implicações para a economia de industrialização recente. In: KIM, L; NELSON, R. R. (org.). Tecnologia, aprendizado e inovação: as experiências das economias de industrialização recente. Campinas-SP: UNICAMP.

TULKENS, H. (1993). An FDH efficiency analsysis: some methodological issues and applications to retail banking, courts, in urban transit. The Journal of Productivity Analysis. v. 4, p. 183- 210.

WOOLDRIDGE, J. M. (2003). Introductory econometrics: a modern approach. 2ed. Washington, DC - USA: South-Western ; Thomson Learning.

WOOLDRIDGE, J. M. (2003). Econometric Analysis of Cross Section and Panel Data. Cambridge, Massachusetts, USA: The MIT Press. 
